\title{
Palmitic acid increases HCK protein and gene expression levels in vascular smoot muscle cells
}

\section{Ghasem Ghasempour}

Iran University of Medical Sciences

\section{Fahimeh Zamani-Garmsiri}

Tehran University of Medical Sciences

\section{Asghar Mohammadi}

Tarbiat Modares University Faculty of Medical Sciences

Mohammad Najafi ( $\nabla$ nbsmmsbn@iums.ac.ir)

Tarbiat Modares University Faculty of Medical Sciences https://orcid.org/0000-0002-0622-4174

\section{Research}

Keywords: Palmitic acid, HCK, VSMC, Proliferation, p-HCK

Posted Date: October 2nd, 2020

DOl: https://doi.org/10.21203/rs.3.rs-84929/v1

License: (c) (i) This work is licensed under a Creative Commons Attribution 4.0 International License. Read Full License 


\section{Abstract}

Background and Aims: Some saturated fatty acids are known to involve in atherosclerosis through different biologic pathways. The aim of this study was to investigate the effects of palmitic acid on the HCK gene and protein expression levels in vascular smooth muscle cells (VSMCs).

Methods and Results: The cells were treated with palmitic acid $(0.5 \mathrm{mM}, 24$ hours) on the cell viability assays. The HCK gene and protein expression levels were measured by real time q-PCR and western blot techniques, respectively. Oil Red $O$ staining method was used to determine the intracellular lipid values. The HCK gene expression level was increased significantly in the PA-treated VSMCs (P 0.02). The total and phosphorylated HCK ( $\mathrm{p}-\mathrm{HCK}$ ) protein expression levels increased in VSMCs. However, there was a significant increase in $\mathrm{p}-\mathrm{HCK}$ value (P 0.001).

Conclusion: The results showed that the palmitic acid increases p-HCK function so that it may affect the VSMC proliferation.

\section{Introduction}

Over the past decades, obesity was considered as a potential risk factor for cardiovascular diseases through different mechanisms involved to adipokines, inflammation, oxidative stress and vessel cellular dysfunction $(1,2)$. Many studies reported that the cardiovascular events relate to the biologic pathways involved in lipid homeostasis $(2,3)$. On considering the life style, the atherogenic effects may improve due to the intake of fatty acids. Some reports have shown that the palmitic acid develops the risk of cardiovascular diseases (4-6). In another study, the serum palmitic acid-related phospholipid fraction was reported to involve with myocardial infarction (7).

In the other hand, it is well known that the endothelial cells (ECs) and vascular smooth muscle cells (VSMCs) are involved in the formation of atherosclerotic plaques. Regarding to some hypotheses, the contractile VSMCs are engaged through phenotypic alteration in order to organize the extracellular matrix (ECM) and to stabilize atherosclerotic plaques (8). Furthermore, the VSMC proliferation plays an important role in vessel stenosis and restenosis (9).

The SRC family (SRC, YES, FYN, LCK, FGR, BLK, LYN, YRK and HCK), known as non-receptor protein tyrosine kinase (SFK), expresses predominantly in mammalian cells. Considering to expression patterns, the SRC, YES and FYN have ubiquitously expressed in the all tissues and cells. Furthermore, the HCK is reported to relate with many cancers such as leukemia, pancreatic, breast, ovarian, prostate, colon and kidney. This protein triggers the cellular proliferation and has a key role in the cellular migration via the remodeling of extracellular matrix. Given its role, HCK therefore can be as a therapeutic target $(10-12)$

Based on the known role of palmitic acid (PA) in the development of cardiovascular diseases (CVD) (13), the aim of this study was to investigate the effects of palmitic acid on the HCK gene and protein expression levels in vascular smooth muscle cells. 


\section{Materials And Methods}

\subsection{Cell culture}

Vascular smooth muscle cells (VSMC C591) were purchased from Pasteur Institute and were cultured in DMEM F-12 enriched with fetal bovine serum (FBS) 10\% and Pen-Strep 1\% using humidified incubator $\left(\mathrm{CO} 2,5 \% ; 37^{\circ} \mathrm{C}\right)$.

\subsection{Cell viability assay}

The effect of palmitic acid on the cell viability was carried out by microculture tetrazolium (MTT) colorimetric assay. Initially, the cells were grown in 96-well plate and were treated with the different concentrations of palmitate $(0,0.1,0.5,1$, and $5 \mathrm{mM})$. After 24 and 48 hours' incubations, the cellular medium was removed and the cells were re-incubated for 2 hours in the presence of MTT solution ( $200 \mu$, $0.5 \mathrm{mg} / \mathrm{ml})$. Then, the produced formazan crystals were dissolved in DMSO (150 $\mu \mathrm{l}$ for 4 hours) and light absorbance was measured at $570 \mathrm{~nm}$ using microplate reader.

\subsection{Treatment}

Palmitic acid was solved in ethanol (1\%), and was added to cultured cells (Confluency, $70 \%$; Dose, $0.5 \mathrm{mM}$ ) for 24 hours. Then, the treated cells were harvested to evaluate the gene and protein expression levels.

\subsection{RNA extraction, cDNA synthesis and RT-qPCR techniques}

Total RNA was isolated from VSMCs using GeneAll-Hybrid-R purification kit (Cat. No. 305 - 101, GeneAll Biotechnology, Seoul, Korea). The quality and quantity of extracted RNA were evaluated using electrophoresis and Nanodrop 2000, respectively. The cDNA was synthesized using Kit (Cat. No. BR631050, BioFACT 2 Step 2X RT-PCR Pre-Mix (Taq), Seoul, Korea). Gene expression quantitative analysis was performed by Applied Biosystems 7500 (Foster City, CA, USA) using Power SYBR Green PCR Master Mix Kit (Cat. No. A190303, Amplicon Denmark). The HCK primers were designed by primer blast (5'CTCTTTGTCCGTGCGAGACT-3', 5'- CCGTCGTTCCCCTTCTTGTA - 3'). GAPDH as a housekeeping gene was used to normalize the HCK gene expression level (Forward Primer: 5'CATGAGAAGTATGACAACAGCCT-3', Reverse Primer: 5'- AGTCCTTCCACGATACCAAAGT-3').

\subsection{Western Blot Analysis}

Total protein was isolated using RIPA buffer containing protease inhibitors. Total protein concentration was measured by micro-lowry Kit (TP0200-1KT, Sigma, USA). The protein fractions were separated on $10 \%$ SDS-polyacrylamide gel (samples $(11 \mu \mathrm{l})$ were loaded on the gel, and were run with voltage $80 \mathrm{~V}$ ) for stacking gel (30 minutes) followed by higher voltage (110 V) for separating gel (60 minutes)) and, then were transferred on a polyvinylidene difluoride (PVDF) membrane (IPVH00010, Merck Millipore, Darmstadt, Germany; 80 V, 60 minutes). After blocking the PVDF membrane using milk blocking solution (5\% milk, 60 minutes, room temperature), it was incubated separately with primary antibodies of HCK (EAB-10359, Elabscience, China), p-Hck (phospho Y522; ab192578, abcam, United Kingdom), and Glyceraldehyde-3-phosphate dehydrogenase (GAPDH) (sc-32233, Santa Cruz Bio-technology, CA, USA) 
overnight at $4{ }^{\circ} \mathrm{C}$. Then, it was followed by the incubation with horseradish peroxidase-conjugated secondary antibody (sc-516102, Santa Cruz Bio-technology, CA, USA; 60 minutes, room temperature). Finally, the protein bands were observed by enhanced chemi-luminescence $(E C L)$ reagent (RPN2235, Amersham, Italy) and were analyzed by Image J software (version $1.51, \mathrm{NIH})$.

\subsection{Oil Red $O$ staining technique}

The intracellular lipid droplets were evaluated using Oil Red O staining method. Briefly, the cells were washed in phosphate-buffered saline (PBS) (2 times) and were fixed in formalin (4\%) at room temperature for 45 minutes. Then, the cells were washed with isopropanol (60\%) for 3 minutes. After adding Oil Red solution (0.1\%, Cat. No. 1320-06-5, Sigma-Aldrich, USA), the cells were incubated at room temperature for 30 minutes. Finally, the cells were rinsed with water ( 3 times) and were observed by model IX71 microscope.

\subsection{Statistical Analysis}

Graph Pad Prism statistical software (v 8.3.0.538, Graphpad, USA) were applied for the data analyses. The differences between groups were determined by using independent samples t-student and MannWhitney tests. The IC50 was calculated in the dose-response way. P value lower than $5 \%$ was considered significant.

\section{Results}

\subsection{Viability vs. Cytotoxicity}

The results showed that the IC50 values are estimated $0.32 \mathrm{mM}$ and $0.52 \mathrm{mM}$ in VSMCs treated with palmitate in the periods of 48 and 24 hours, respectively (Fig. 1).

\subsection{HCK gene expression level}

The HCK expression level increased significantly up to 3.2 times in treated cells with palmitate as compared with control group (P 0.0286) (Fig. 2).

\subsection{HCK protein expression level}

In the converse with the total HCK protein expression level (P 0.8139) (Fig. 3. A), the phosphorylated HCK protein value increased significantly in the treated cells with palmitate (P 0.0012) (Fig. 3. B).

\section{4. p-HCK/total HCK ratio}

The $\mathrm{p}-\mathrm{HCK} / \mathrm{HCK}$ ratio in the palmitate-treated group increased significantly as compare to control ( $\mathrm{P}$ 0.001) (Fig. 4, A vs. B).

\subsection{Cellular lipid}

The intracellular lipid distribution in VSMCs treated with palmitate $(0.5 \mathrm{mM}, 24$ hours $)$ increased as compared with controls (Fig. 5). 


\section{Discussion}

Palmitic acid has the endogenous and exogenous sources in the body. This saturated fatty acid makes up about $44 \%$ of palm oil, $65 \%$ of butter, $53 \%$ of tallow, $15 \%$ of soybean, $13 \%$ of corn oil, and $17 \%$ of olive oil (9). It is also known as an atherogenic agent in the improvement of cardiovascular diseases in obesity (15). Thus, the role of palmitic acid in the proliferation and migration of VSMCs (14) maybe interesting. In this study, the HCK gene and protein expression levels was studied in the palmitate-treated VSMCs since the HCK is known to be involved in the cellular proliferative and adhesive pathways.

The many evidence indicated that some free fatty acids are able to proliferate VSMCs $(16,17)$ resulted in the development of atherosclerosis process in the rat and human $(18,19)$.

It is reported that PA causes the cardiomyocyte hypertrophy via phosphorylation of PCKZ and its interaction with STAT3 (20). Furthermore, it developed the melanoma by involving cellular proliferative pathways via the phosphorylation of Akt (21). The promotion of cancer invasiveness was also suggested by the activation of TLR4/ROS/NFKB/MMP9-related signaling pathways (22). It is suggested that PA modifies the protein sequences by phosphorylation of tyrosine residues (23). On the confirmation of above studies, this study showed that PA increases the HCK gene expression level improving of the cellular proliferation pathways. Furthermore, the p-HCK protein expression level increased in PA-treated VSMCs on the role of PA in the modification of amino acid residues. However, the HCK protein expression level increased in PA-treated VSMCs but it was not significantly as compared to control. It is proposed that the HCK protein synthesis is not in accordance with the gene expression level so that we suggested that the activation of HCK phosphorylation (p-HCK) prevents significantly from the total HCK synthesis. In the other hand, PA may affect the HCK-involved signaling pathways by the phosphorylation of HCK in a fast-response way. Since other studies reported that HCK elevates via the function of BCR/ABL, TEL/ABL, EGFR /PDGFR, and PI3K/Akt $(10,24)$ thus it is an impotent factor in the activation of the cellular proliferation and adhesive pathways.

\section{Conclusion}

This study suggested that palmitic acid increases the cellular proliferation pathway in VSMCs via the function of phosphorylated HCK (p-HCK).

\section{Abbreviations}

Phosphorylated HCK; p-HCK, Vascular smooth muscle cells; VSMCs, Endothelial cells; ECs, Extracellular matrix; ECM, Palmitic acid; PA, Cardiovascular diseases; CVD

\section{Declarations}

Ethics approval and consent to participate: It was approved by the Committee on the Ethics of IUMS. 
Consent for publication: No

Availability of data and material: It is presented on the request from corresponding Author.

\section{Competing interests: No}

Funding: The part of work was supported by IUMS (No. 14467).

Authors' contributions: M.N and G.G designed the study; G,G, F.Z.G and A.M evaluated the gene and protein expression levels. M.N and G.G analyzed the data.

Acknowledgements: No.

\section{References}

1. Bosello O, Donataccio MP, Cuzzolaro M. Obesity or obesities? Controversies on the association between body mass index and premature mortality. Eating and Weight Disorders-Studies on Anorexia, Bulimia and Obesity. 2016;21(2):165-74.

2. Lovren $\mathrm{F}$, Teoh $\mathrm{H}$, Verma S. Obesity and atherosclerosis: mechanistic insights. Canadian Journal of Cardiology. 2015;31(2):177-83.

3. Jin J-L, Guo Y-L, Li J-J. Plasma free fatty acids in relation with the severity of coronary artery disease in non-diabetics: a Gensini score assessment. IJC Metabolic \& Endocrine. 2017;14:48-52.

4. Afonso MS, Lavrador MSF, Koike MK, Cintra DE, Ferreira FD, Nunes VS, et al. Dietary interesterified fat enriched with palmitic acid induces atherosclerosis by impairing macrophage cholesterol efflux and eliciting inflammation. The Journal of nutritional biochemistry. 2016;32:91-100.

5. Brown E. Cruel Oil. How palm oil harms health, rainforest and wildlife. Center of Science in the Public Interest, 2005.

6. Kabagambe EK, Baylin A, Ascherio A, Campos H. The type of oil used for cooking is associated with the risk of nonfatal acute myocardial infarction in Costa Rica. The Journal of nutrition. 2005;135(11):2674-9.

7. Siniarski A, Rostoff P, Rychlak R, Krawczyk K, Gołębiowska-Wiatrak R, Mostowik M, et al. Unsaturated fatty acid composition in serum phospholipids in patients in the acute phase of myocardial infarction. Kardiologia polska. 2019;77(10):935-43.

8. Basatemur GL, Jørgensen HF, Clarke MC, Bennett MR, Mallat Z. Vascular smooth muscle cells in atherosclerosis. Nature reviews cardiology. 2019:1-18.

9. Fatima S, Hu X, Gong R-H, Huang C, Chen M, Wong HLX, et al. Palmitic acid is an intracellular signaling molecule involved in disease development. Cellular and Molecular Life Sciences. 2019:111.

10. Poh AR, O'Donoghue RJ, Ernst M. Hematopoietic cell kinase (HCK) as a therapeutic target in immune and cancer cells. Oncotarget. 2015;6(18):15752. 
11. Roseweir AK, Powell AG, Horstman SL, Inthagard J, Park JH, McMillan DC, et al. Src family kinases, HCK and FGR, associate with local inflammation and tumour progression in colorectal cancer. Cellular signalling. 2019;56:15-22.

12. DA JDFFB, Sant'Anna CDC, Muniz JAPC, DA ROCHA CAM, Lamarao LM, NUNES CDFAM, et al. Deregulation of the SRC family tyrosine kinases in gastric carcinogenesis in non-human primates. Anticancer research. 2018;38(11):6317-20.

13. Ebbesson SO, Voruganti VS, Higgins PB, Fabsitz RR, Ebbesson LO, Laston S, et al. Fatty acids linked to cardiovascular mortality are associated with risk factors. International journal of circumpolar health. 2015;74(1):28055.

14. Rocha VZ, Libby P. Obesity, inflammation, and atherosclerosis. Nature Reviews Cardiology. 2009;6(6):399.

15. Zdychova J, Cejkova S, Lesna IK, Kralova A, Maluskova J, Janousek L, et al. Co-cultivation of human aortic smooth muscle cells with epicardial adipocytes affects their proliferation rate. Physiological research. 2014;63:S419.

16. Lamers D, Schlich R, Greulich S, Sasson S, Sell H, Eckel J. Oleic acid and adipokines synergize in inducing proliferation and inflammatory signalling in human vascular smooth muscle cells. Journal of cellular and molecular medicine. 2011;15(5):1177-88.

17. Lu G, Morinelli TA, Meier KE, Rosenzweig SA, Egan BM. Oleic acid-induced mitogenic signaling in vascular smooth muscle cells: a role for protein kinase C. Circulation research. 1996;79(3):611-9.

18. Ross R. The pathogenesis of atherosclerosis: a perspective for the 1990s. Nature. 1993;362(6423):801-9.

19. Raman P, Madhavpeddi L, Gonzales RJ. Palmitate induces glycosylation of cyclooxygenase-2 in primary human vascular smooth muscle cells. American Journal of Physiology-Cell Physiology. 2018;314(5):C545-C53.

20. Chen YP, Kuo WW, Baskaran R, Day CH, Chen RJ, Wen SY, et al. Acute hypoxic preconditioning prevents palmitic acid-induced cardiomyocyte apoptosis via switching metabolic GLUT4-glucose pathway back to CD36-fatty acid dependent. Journal of cellular biochemistry. 2018;119(4):3363-72.

21. Röhrig F, Schulze A. The multifaceted roles of fatty acid synthesis in cancer. Nature Reviews Cancer. 2016;16(11):732.

22. Binker-Cosen MJ, Richards D, Oliver B, Gaisano HY, Binker MG, Cosen-Binker LI. Palmitic acid increases invasiveness of pancreatic cancer cells AsPC-1 through TLR4/ROS/NF-KB/MMP-9 signaling pathway. Biochemical and biophysical research communications. 2017;484(1):152-8.

23. Dittmann A, Kennedy NJ, Soltero NL, Morshed N, Mana MD, Yilmaz ÖH, et al. High-fat diet in a mouse insulin-resistant model induces widespread rewiring of the phosphotyrosine signaling network. Molecular Systems Biology. 2019;15(8).

24. Suh H-S, Kim M-O, Lee SC. Inhibition of granulocyte-macrophage colony-stimulating factor signaling and microglial proliferation by anti-CD45RO: role of Hck tyrosine kinase and phosphatidylinositol 3kinase/Akt. The Journal of Immunology. 2005;174(5):2712-9. 
Figures

A

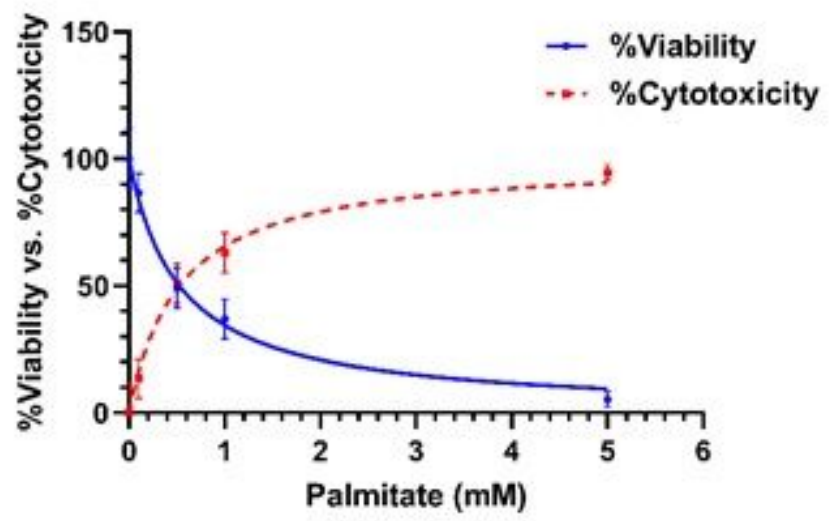

B

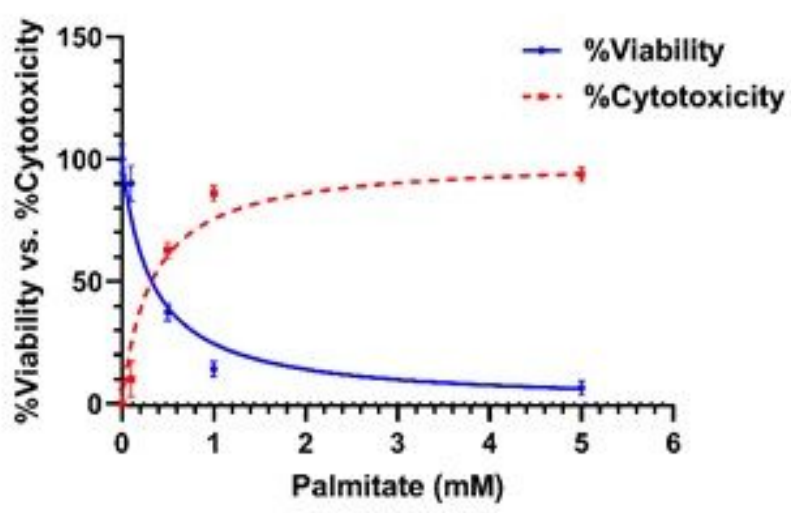

\section{Figure 1}

IC50 values in VSMCs treated with palmitate. A, The cell treatment in 24 hours. B, The cell treatment in 48 hours

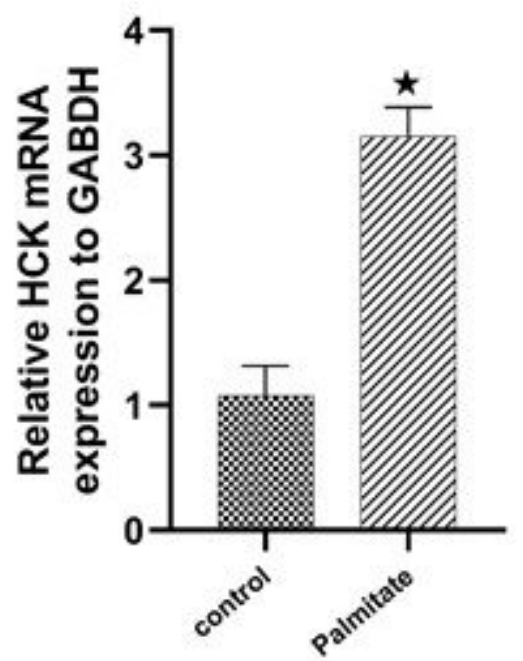

Figure 2

HCK gene expression level. 
A

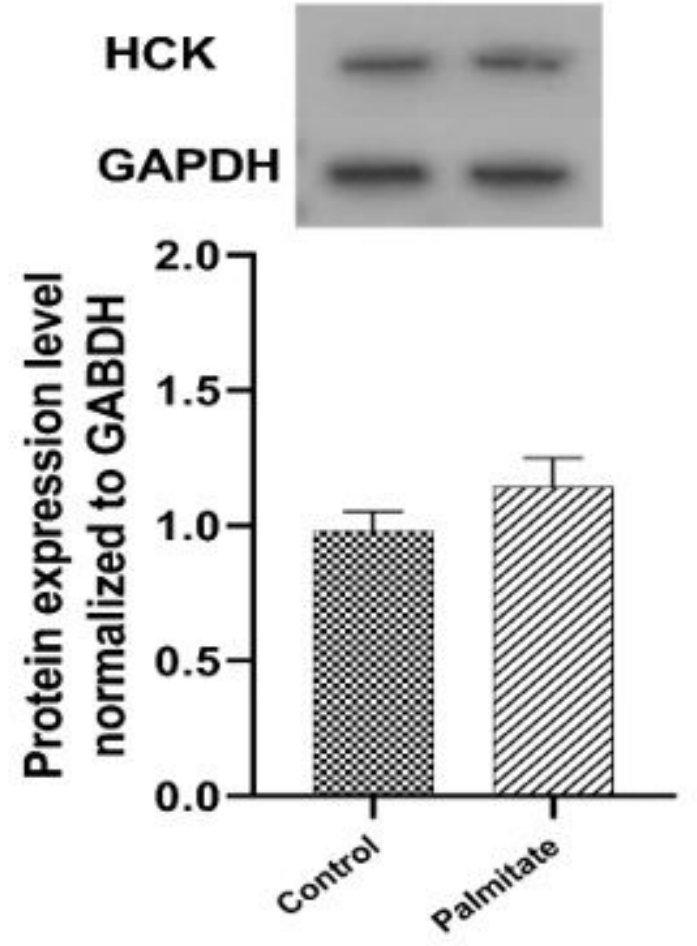

B

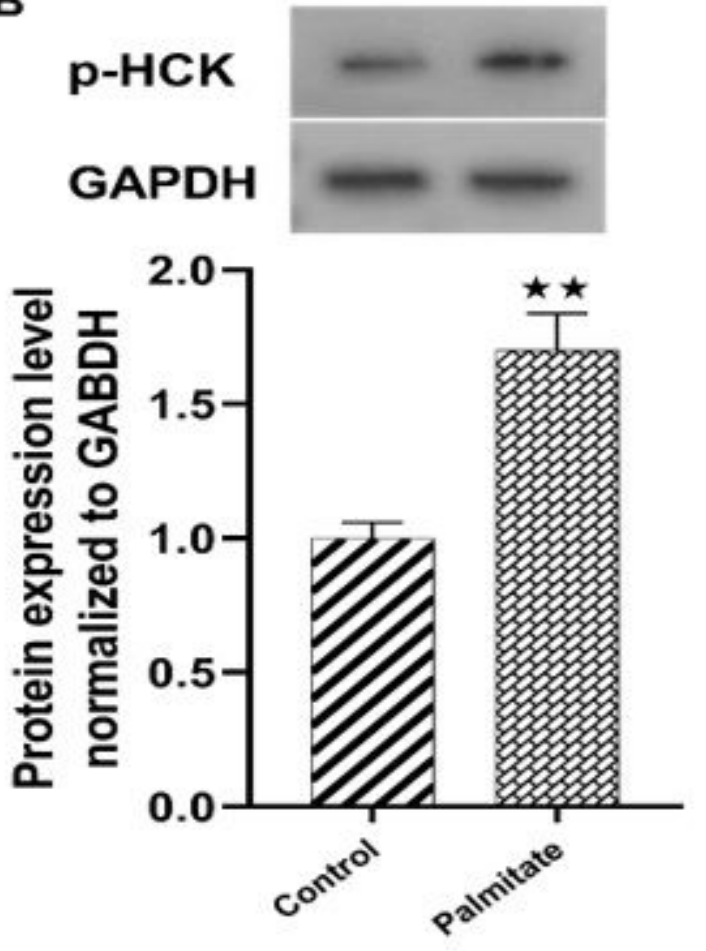

Figure 3

Total and phosphorylated HCK Protein expression levels. A, total HCK protein level. B, p-HCK

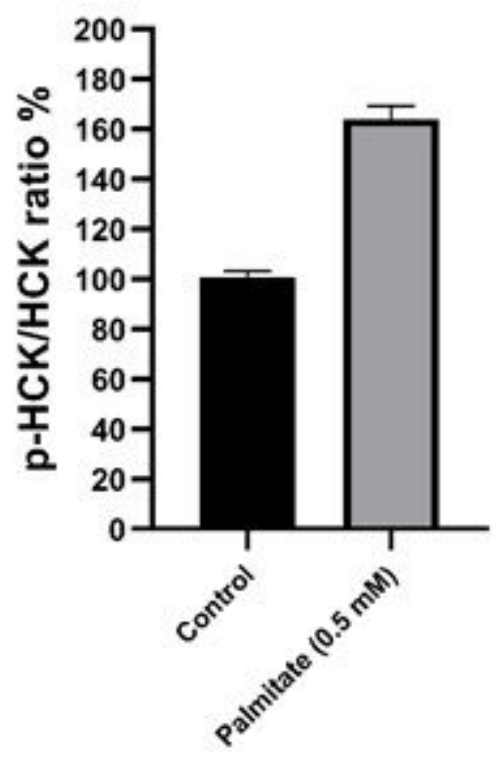

Figure 4

p-HCK/HCK ratio. 


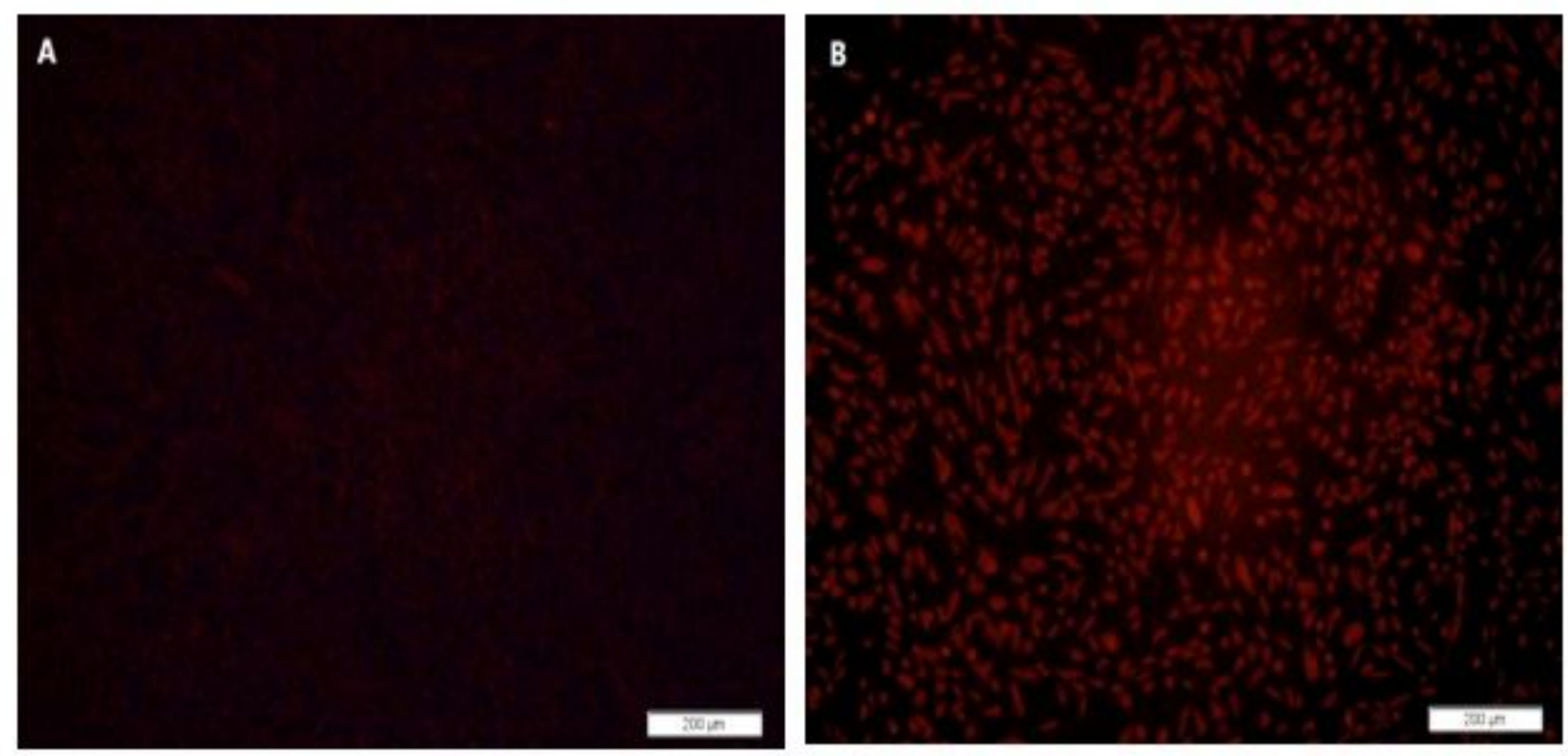

\section{Figure 5}

Cellular lipid distribution. A, VSMCs. B, Palmitate-treated VSMCs. 